Article

\title{
Computational and Experimental Investigation of Micro-Hardness and Wear Resistance of Ni-Based Alloy and TiC Composite Coating Obtained by Laser Cladding
}

\author{
Guofu Lian ${ }^{1}$, Hao Zhang ${ }^{1}$, Yang Zhang ${ }^{2, *}$, Mingpu Yao ${ }^{1}$, Xu Huang ${ }^{1,3}$ \\ and Changrong Chen ${ }^{1,3}$ D \\ 1 School of Mechanical \& Automotive Engineering, Fujian University of Technology, Fuzhou 350118, China; \\ gflian@mail.ustc.edu.cn (G.L.); zhanghao573@163.com (H.Z.); mpyao@smail.fjut.edu.cn (M.Y.); \\ huangxu@fjut.edu.cn (X.H.); changrong.chen@fjut.edu.cn (C.C.) \\ 2 School of Engineering + Technology, Western Carolina University, Cullowhee, NC 28723, USA \\ 3 Digital Fujian Industrial Manufacturing IoT Lab, Fuzhou 350118, China \\ * Correspondence: yzhang@wcu.edu; Tel.: +1-(828)-227-2564
}

Received: 3 February 2019; Accepted: 3 March 2019; Published: 7 March 2019

\begin{abstract}
The influence of processing parameters on the micro-hardness and wear resistance of a Ni-based alloy and titanium carbide (TiC) composite cladding layer was studied. Mathematical models were developed to predict the micro-hardness and wear resistance of the cladding layer by controlling the laser cladding processing parameters. Key processing parameters were the laser power, scanning speed, gas flow, and TiC powder ratio. The models were validated by analysis of variance and parameter optimization. Results show that the micro-hardness is positively correlated with laser power and $\mathrm{TiC}$ powder ratio, where the $\mathrm{TiC}$ powder ratio shows the most significant impact. The wear volume decreased with an increasing $\mathrm{TiC}$ powder ratio. The targets for the processing parameter optimization were set to $62 \mathrm{HRC}$ for micro-hardness and a minimal volume wear. The difference between the model prediction value and experimental validation result for micro-hardness and wear volume were $1.87 \%$ and $6.33 \%$, respectively. These models provide guidance to optimize the processing parameters to achieve a desired micro-hardness and maximize wear resistance in a composite cladding layer.
\end{abstract}

Keywords: Ni35A + TiC composite; laser cladding; central composite design; micro-hardness; wear resistance

\section{Introduction}

Laser cladding is a surface modification technology that is used to enhance the mechanical properties of a substrate. In this process, a thin layer of metal powder is placed on the surface of the substrate and both the powder and substrate are melted with a laser beam to form a cladding layer [1,2]. Due to its modest heat affected zone, small-scale deformation, low dilution rate, and rapid melting and solidification, laser cladding has been widely applied to repair and remanufacture crank shaft and other high value parts in the aerospace, marine, petroleum, and chemical industries [3-5].

Recent development in laser cladding powders and surface coatings has been extended beyond traditional materials to include composite materials. For instance, $\mathrm{NiCrSiB}$ series alloys are extensively utilized in industry due to their exceptional corrosion, wear and fatigue resistance, and cost efficiency [6-8]. Within this series, most of the research has focused on Ni60A powder. However, Ni60A has high brittleness, which could lead to a high possibility of fracture. Ni35A possesses high plasticity 
but low hardness. However, its hardness could be improved by incorporating add-on materials [9]. $\mathrm{TiC}$ has a high melting point, high hardness, outstanding wear resistance, and a low coefficient of friction. Thus, TiC has been frequently adopted to enhance material properties [10,11]. Because of the phenomenal properties, research has been concentrated on combining nickel-based alloys and TiC to form composite cladding materials.

Bakkar et al. investigated the microstructure, micro-hardness, wear resistance, and corrosion resistance of different volume percentages of TiC/Inconel 625 nickel-based composite alloys. They found that the micro-hardness and wear resistance of these type of composites could be improved by adding an appropriate volume fraction of TiC [12]. Muvvala et al. conducted laser cladding experiments with different weight percentages of TiC/Inconel 718 nickel-based composite alloy powder and investigated the impact of processing parameters on the molten pool and structural properties. Analyzing the result illustrated that optimizing processing parameters could effectively disperse fine TiC particles, which enhanced hardness and wear resistance of the cladding layer [13]. Liu et al. produced a TiC enhanced nickel-based composite coating. They concluded that the phase and distribution of TiC were affected by convection in the molten pool [14]. Saroj et al. created a TiC-Inconel 825 composite coating employing a Tungsten Inert Gas (TIG) cladding method and discovered the impact of different $\mathrm{TiC}$ percentages $(20 \%, 40 \%$, and $60 \%)$ and processing currents on the coating morphology, micro-hardness, and wear resistance. Because of the superior wettability and binding between nickel-based alloys and $\mathrm{TiC}$, the coating hardness reached $1100 \mathrm{HV}_{0.05}$, and the wear resistance improved seven times over that of the substrate [15]. Sahoo et al. also utilized TIG cladding to build TiC-Ni composite coating on an AISI304 steel substrate. The results exhibited outstanding binding between the coating and substrate, the hardness reached $1300 \mathrm{HV}_{0.05}$, and the wear resistance increased 70 times with TiC-Ni composite coating when compared to the substrate [16].

Existing research on a nickel-based alloy and TiC composite material are primarily focused on the influence of different $\mathrm{TiC}$ ratios and processing parameters on the structural properties, micro-hardness, and wear resistance of the coating since micro-hardness and wear resistance are two important factors evaluated in industrial applications. However, predicting and controlling the cladding layer micro-hardness and wear resistance by manipulating the laser cladding processing parameters and $\mathrm{TiC}$ ratio have rarely been explored. In this paper, mathematical models are developed to predict the micro-hardness and wear resistance of the cladding layer by controlling the laser cladding processing parameters and $\mathrm{TiC}$ powder ratio.

\section{Materials and Methods}

AISI/SAE 1045 steel was selected as the substrate with a size of $40 \mathrm{~mm} \times 20 \mathrm{~mm} \times 5 \mathrm{~mm}$. The laser beam diameter was adjusted to $4 \mathrm{~mm}$. Cladding powder was made from Ni35A and TiC powder with a particle size ranging from $48 \mu \mathrm{m}$ to $106 \mu \mathrm{m}$. The elemental composition and morphology of Ni35A and $\mathrm{TiC}$ power are shown in Table 1 and Figure 1.

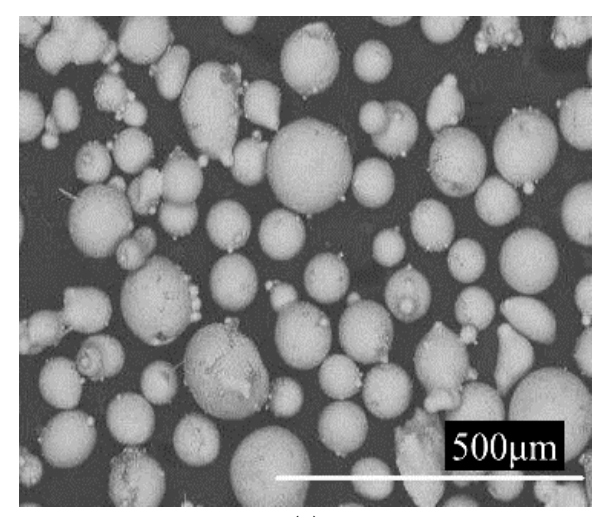

(a)

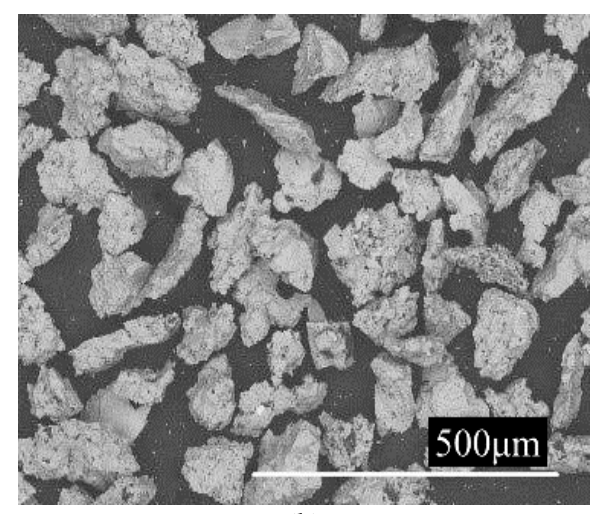

(b)

Figure 1. (a) Morphology of Ni35A powder. (b) Morphology of TiC powder. 
Table 1. Elemental composition (wt.\%) of Ni35A and TiC powder.

\begin{tabular}{ccccccccccc}
\hline \multirow{2}{*}{ Powder } & \multicolumn{10}{c}{ Element (wt.\%) } \\
\cline { 2 - 11 } & $\mathbf{C}$ & $\mathbf{S i}$ & $\mathbf{O}$ & Fe & Cr & B & T.C & F.C & N & Ni \\
\hline Ni35A & 0.32 & 3.35 & $<0.05$ & 2.75 & 7.75 & 1.65 & - & - & - & Rest \\
$\mathrm{TiC}$ & - & 0.02 & 0.5 & 0.08 & - & - & $>18.8$ & $<0.5$ & 0.5 & - \\
\hline
\end{tabular}

Figure 2 explains the laser cladding system, which includes a laser system (YLS-3000, IPG, Burbach, Germany), laser cladding nozzle with $300 \mathrm{~mm}$ focal length (FDH0273, Lasermech, Novi, MI, USA), industrial robot (M-710iC/50, FANUC, Yamanashi, Japan), water cooling system (TFLW-4000WDR-01-3385, Sanhe Tongfei, Sanhe, China), powder feeding system (CR-PGF-D-2, Songxing, Fuzhou, China), control system (PLC, Mitsubishi, Japan), and laser pulse control system (SX14-012PULSE, IPG, Burbach, Germany). Argon gas was used to protect the material during the cladding process.

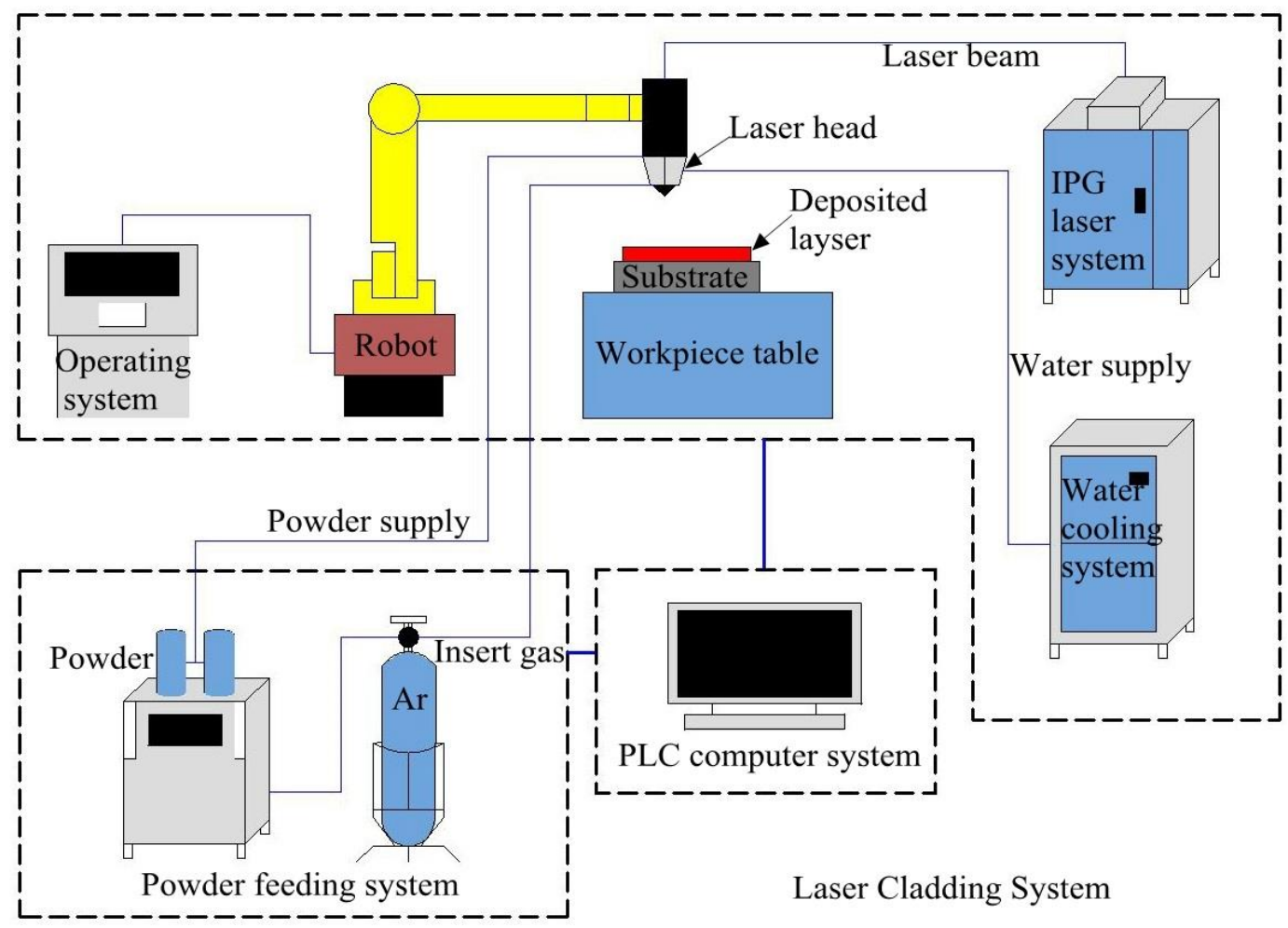

Figure 2. Laser cladding system.

Before cladding, the 1045 steel substrate surface was cleaned with ethanol. The Ni35A and TiC powder was mixed in a MITR-YXQM-2L ball mill machine (MITR, Changsha, China) for 30 min at a speed of $300 \mathrm{rpm}$ and then placed in a vacuum dryer for an additional $30 \mathrm{~min}$ at a temperature of $120{ }^{\circ} \mathrm{C}$. After completion of the laser cladding, the sample was processed by cutting, setting, grinding, and polishing. Then the sample was immersed in $4 \%$ nitric acid and alcohol mixture for $30 \mathrm{~s}$. An MVA-402TS micro-hardness tester (HDNS, Shanghai, China) was utilized to measure the micro-hardness with a $500 \mathrm{~g}$-force applied for a 30-s duration. The microstructure was observed using a scanning electron microscope (SEM) TM3030Plus (HITACHI 550I, Tokyo, Japan). In addition, element analysis was performed using an energy-dispersive X-ray spectroscopy (EDS) system (A550I, IXRF, Austin, TX, USA). The wear resistance was examined with a UMT-2 high load scratch tester (Bruker, Billerica, MA, USA). The X-ray diffraction (XRD) analysis was conducted with Ultima IV XRD systems (Rigaku Corporation, Tokyo, Japan). 3D morphology of the abrasion surface was obtained using white light interferometry. Afterwards, the width and depth of the worn area was measured. 
The average wear off area was obtained by repeating the previously mentioned measurement in five different locations. In the end, wear volume was calculated by multiplying the average wear off area by the scratching distance. The wear volume was used to evaluate wear resistance in which lower wear volume indicates greater wear resistance. The friction coefficient was measured every $0.1 \mathrm{~s}$ over a duration of $60 \mathrm{~min}$. Conditions for the wear test are shown below in Table 2.

Table 2. Scratch testing parameters.

\begin{tabular}{ccc}
\hline Parameters & Unit & Specifications \\
\hline Friction pair & $\mathrm{mm}$ & Cemented Carbide- $\Phi 6 \mathrm{~mm}$ \\
Force & $\mathrm{N}$ & 35 \\
Speed & $\mathrm{mm} / \mathrm{s}$ & 10 \\
Distance & $\mathrm{mm}$ & 60 \\
Duration & $\mathrm{min}$ & Reciprocating \\
Mode & - & Room temperature \\
Temperature & ${ }^{\circ} \mathrm{C}$ & \\
\hline
\end{tabular}

Respond surface methodology (RSM) is an optimization method that can be used to build a mathematic model between output and input variables. In this study, the central composite design (CCD) module in RSM was selected. The experimental design matrix contained four factors and five levels. The four factors were laser power (LP), scanning speed (SS), gas flow (GF), and TiC powder ratio (PR). The variables for the factors were set to $0, \pm 1$, and \pm 2 in the Design Expert software (Version 10.0). Then the interaction respond value between input and output was obtained with the CCD design. The intent of RSM is to build a statistical prediction model based on experimental results. Afterwards, analysis of variance was utilized to analyze the model [17]. Multiple regression analysis was employed to build and analyze the model between the input parameters and the output. The polynomial regression function is shown in Equation (1) below [18], where y is the response value and $\beta_{0}$ is the intercept factor. The coefficients for the linear term, interaction term, and quadratic term are $\beta_{j}, \beta_{i j}, \beta_{j j}$, respectively. Additionally, $x_{i}$ and $x_{j}$ represent the processing parameter, $k$ is the number of factors, and $\varepsilon$ is the residual.

$$
y=\beta_{0}+\sum_{j=1}^{k} \beta_{j} x_{j}+\sum_{i, j=1}^{k} \beta_{i j} x_{i} x_{j}+\sum_{j=1}^{k} \beta_{j j} x_{j}^{2}+\varepsilon
$$

The laser cladding processing parameter variables are exhibited in Table 3. Experimental design and results are shown in Table 4.

Table 3. Laser cladding processing parameter variables.

\begin{tabular}{|c|c|c|c|c|c|c|c|c|}
\hline \multirow{2}{*}{ Variables } & \multirow{2}{*}{ Notation } & \multirow{2}{*}{ Unit } & \multicolumn{6}{|c|}{ Levels of Input Variables } \\
\hline & & & Code & -2 & -1 & 0 & 1 & 2 \\
\hline Laser power & LP & $\mathrm{kW}$ & \multirow{4}{*}{ Actual } & 1.1 & 1.2 & 1.3 & 1.4 & 1.5 \\
\hline Scanning speed & SS & $\mathrm{mm} / \mathrm{s}$ & & 4 & 5 & 6 & 7 & 8 \\
\hline Gas flow & GF & $\mathrm{L} / \mathrm{h}$ & & 800 & 1000 & 1200 & 1400 & 1600 \\
\hline $\mathrm{TiC}$ powder ratio & PR & wt. $\%$ & & 0 & 20 & 40 & 60 & 80 \\
\hline
\end{tabular}

Table 4. CCD experimental design and results.

\begin{tabular}{ccccccc}
\hline Run & LP (kW) & SS (mm/s) & GF (L/h) & PR (wt. $\%)$ & $\begin{array}{c}\text { Micro-Hardness } \\
(\mathbf{H R C})\end{array}$ & $\begin{array}{c}\text { Wear Volume } \\
\left(\mathbf{\mu m}^{\mathbf{3}}\right)\end{array}$ \\
\hline 1 & 1.4 & 5 & 1400 & 60 & 75.18 & 1386.04 \\
2 & 1.2 & 7 & 1000 & 20 & 55.70 & 8076.80 \\
3 & 1.3 & 6 & 800 & 40 & 67.02 & 5840.25 \\
\hline
\end{tabular}


Table 4. Cont.

\begin{tabular}{|c|c|c|c|c|c|c|}
\hline Run & LP (kW) & $\mathrm{SS}(\mathrm{mm} / \mathrm{s})$ & GF (L/h) & PR (wt.\%) & $\begin{array}{c}\text { Micro-Hardness } \\
\text { (HRC) }\end{array}$ & $\begin{array}{l}\text { Wear Volume } \\
\qquad\left(\mu \mathrm{m}^{3}\right)\end{array}$ \\
\hline 4 & 1.4 & 7 & 1000 & 20 & 57.50 & $10,499.10$ \\
\hline 5 & 1.4 & 5 & 1000 & 20 & 57.78 & 5877.28 \\
\hline 6 & 1.3 & 6 & 1200 & 40 & 63.68 & 5116.18 \\
\hline 7 & 1.4 & 7 & 1000 & 60 & 74.32 & 1659.55 \\
\hline 8 & 1.4 & 5 & 1000 & 60 & 73.04 & 669.07 \\
\hline 9 & 1.2 & 5 & 1000 & 60 & 70.14 & 3582.03 \\
\hline 10 & 1.4 & 5 & 1400 & 20 & 57.12 & 8248.70 \\
\hline 11 & 1.2 & 5 & 1400 & 60 & 71.48 & 1221.86 \\
\hline 12 & 1.3 & 6 & 1200 & 80 & 74.54 & 518.22 \\
\hline 13 & 1.2 & 5 & 1000 & 20 & 59.44 & $14,804.70$ \\
\hline 14 & 1.3 & 6 & 1200 & 40 & 66.06 & 6982.62 \\
\hline 15 & 1.3 & 6 & 1200 & 40 & 70.88 & 6938.96 \\
\hline 16 & 1.4 & 7 & 1400 & 60 & 72.42 & 3408.27 \\
\hline 17 & 1.2 & 7 & 1000 & 60 & 70.88 & 5854.99 \\
\hline 18 & 1.3 & 6 & 1200 & 40 & 65.30 & 6821.46 \\
\hline 19 & 1.2 & 5 & 1400 & 20 & 54.04 & $15,654.50$ \\
\hline 20 & 1.2 & 7 & 1400 & 20 & 58.64 & $10,248.70$ \\
\hline 21 & 1.4 & 7 & 1400 & 20 & 59.70 & $11,030.70$ \\
\hline 22 & 1.3 & 6 & 1200 & 0 & 45.98 & $16,519.10$ \\
\hline 23 & 1.3 & 6 & 1200 & 40 & 69.70 & 7145.65 \\
\hline 24 & 1.5 & 6 & 1200 & 40 & 67.60 & 7670.22 \\
\hline 25 & 1.3 & 6 & 1200 & 40 & 65.40 & 8012.80 \\
\hline 26 & 1.3 & 4 & 1200 & 40 & 69.16 & 6209.50 \\
\hline 27 & 1.1 & 6 & 1200 & 40 & 64.72 & 6772.47 \\
\hline 28 & 1.3 & 8 & 1200 & 40 & 64.68 & 9153.11 \\
\hline 29 & 1.2 & 7 & 1400 & 60 & 68.12 & 2962.03 \\
\hline 30 & 1.3 & 6 & 1600 & 40 & 67.54 & 9341.54 \\
\hline
\end{tabular}

\section{Results and Discussion}

\subsection{Analysis of Variance}

Variance analysis of micro-hardness and wear volume (Tables 5 and 6) was used to examine the reasonableness of the selected model. Note that, for the micro-hardness model, its P-value is less than 0.0001 and the lack of fit is larger than 0.05 . These results indicate that there is only a 0.0001 probability of causing interference. The adequate precision (signal-to-noise ratio) value of 29.479 is larger than 4 , which indicates that model accuracy is satisfied. The closer the value of R-Square to 1 is, the better fit the model is. The R-Square value of this model is 0.9447. In addition, the Adjusted R-Square and Predicted R-Square values are both close to 1 and the difference between these two values is 0.0176 , which is less than the needed value of 0.2 [18]. These results demonstrate that this model has a high level of fit and could be used to precisely predict the correlation between processing parameters and micro-hardness. Similarly, the wear volume model also meets these expectations.

In Table 5, it can be seen that the $\mathrm{TiC}$ powder ratio and its quadratic term are the dominant factors in the micro-hardness model. Laser power has a moderate effect and the effect of scanning speed is negligible. It is evident from Table 6 that the TiC powder ratio is also the most significant parameter in the wear volume model. The micro-hardness and wear volume models are shown below in Equations (2) and (3), where LP is laser power, SS is scanning speed, and PR is the TiC powder ratio. LP $\times$ SS, $\mathrm{LP} \times \mathrm{SS}$, and SS $\times \mathrm{PR}$ are the interaction terms. The quadratic term of the powder ration is represented by $\mathrm{PR}^{2}$.

$$
\begin{aligned}
\text { Microhardness }= & 58.20639-12.09167 \times \mathrm{LP}-1.60125 \times \mathrm{SS}+0.42509 \times \mathrm{PR}+1.61250 \\
& \times \mathrm{LP} \times \mathrm{SS}+0.31438 \times \mathrm{LP} \times \mathrm{PR}-0.22687 \times \mathrm{SS} \times \mathrm{PR}-4.2218 \times 10^{-3} \\
& \times \mathrm{PR}^{2}
\end{aligned}
$$




$$
\begin{aligned}
\text { Wear Volume }= & 1.33239 \times 10^{5}-85232.58542 \times \mathrm{LP}-16189.90302 \times \mathrm{SS}-736.06472 \\
& \times \mathrm{PR}+11585.69688 \times \mathrm{LP} \times \mathrm{SS}+207.21641 \times \mathrm{LP} \times \mathrm{PR}+36.73658 \times \mathrm{SS} \\
& \times \mathrm{PR}+0.58615 \times \mathrm{PR}^{2}
\end{aligned}
$$

\begin{tabular}{|c|c|c|c|c|c|c|}
\hline Source & $\begin{array}{l}\text { Sum of } \\
\text { Squares }\end{array}$ & $\begin{array}{l}\text { Degree of } \\
\text { Freedom }\end{array}$ & $\begin{array}{l}\text { Mean } \\
\text { Square }\end{array}$ & F Value & $\begin{array}{l}p \text {-Value } \\
\text { Prob > F }\end{array}$ & \\
\hline Model & 1364.86 & 7 & 194.98 & 53.68 & $<0.0001$ & Significant \\
\hline LP & 24.77 & 1 & 24.77 & 6.82 & 0.0159 & \\
\hline SS & 4.08 & 1 & 4.08 & 1.12 & 0.3005 & \\
\hline PR & 1243.87 & 1 & 1243.87 & 342.46 & $<0.0001$ & \\
\hline $\mathrm{LP} \times \mathrm{SS}$ & 0.42 & 1 & 0.42 & 0.11 & 0.7382 & \\
\hline $\mathrm{LP} \times \mathrm{PR}$ & 6.33 & 1 & 6.33 & 1.74 & 0.2005 & \\
\hline $\mathrm{SS} \times \mathrm{PR}$ & 3.29 & 1 & 3.29 & 0.91 & 0.3513 & \\
\hline $\mathrm{PR}^{2}$ & 82.11 & 1 & 82.11 & 22.61 & $<0.0001$ & \\
\hline Residual & 79.91 & 22 & 3.63 & - & - & \\
\hline Lack of Fit & 40.37 & 17 & 2.37 & 0.30 & 0.9719 & Not significant \\
\hline Pure Error & 39.54 & 5 & 7.91 & - & - & \\
\hline Cor Total & 1444.77 & 29 & & - & - & \\
\hline $\mathrm{R}^{2}$ & & 0.9447 & & $\operatorname{Adj} R^{2}$ & & 0.9271 \\
\hline Pred $\mathrm{R}^{2}$ & & 0.9068 & & Adeq Precision & & 29.479 \\
\hline
\end{tabular}

Table 5. Analysis of variance on micro-hardness.

\begin{tabular}{|c|c|c|c|c|c|c|}
\hline Source & $\begin{array}{l}\text { Sum of } \\
\text { Squares }\end{array}$ & $\begin{array}{l}\text { Degree of } \\
\text { Freedom }\end{array}$ & $\begin{array}{l}\text { Mean } \\
\text { Square }\end{array}$ & F Value & $\begin{array}{l}p \text {-Value } \\
\text { Prob > F }\end{array}$ & \\
\hline Model & $4.321 \times 10^{8}$ & 7 & $6.172 \times 10^{7}$ & 18.81 & $<0.0001$ & Significant \\
\hline LP & $1.325 \times 10^{7}$ & 1 & $1.325 \times 10^{7}$ & 4.04 & 0.0570 & \\
\hline SS & $2.790 \times 10^{6}$ & 1 & $2.790 \times 10^{6}$ & 0.85 & 0.3665 & \\
\hline PR & $3.816 \times 10^{8}$ & 1 & $3.816 \times 10^{8}$ & 116.26 & $<0.0001$ & \\
\hline $\mathrm{LP} \times \mathrm{SS}$ & $2.148 \times 10^{7}$ & 1 & $2.148 \times 10^{7}$ & 6.54 & 0.0179 & \\
\hline $\mathrm{LP} \times \mathrm{PR}$ & $2.748 \times 10^{6}$ & 1 & $2.748 \times 10^{6}$ & 0.84 & 0.3701 & \\
\hline $\mathrm{SS} \times \mathrm{PR}$ & $8.637 \times 10^{6}$ & 1 & $8.637 \times 10^{6}$ & 2.63 & 0.1190 & \\
\hline $\mathrm{PR}^{2}$ & $1.583 \times 10^{6}$ & 1 & $1.583 \times 10^{6}$ & 0.48 & 0.4946 & \\
\hline Residual & $7.221 \times 10^{7}$ & 22 & $3.282 \times 10^{6}$ & - & - & \\
\hline Lack of Fit & $6.774 \times 10^{7}$ & 17 & $3.985 \times 10^{6}$ & 4.46 & 0.0531 & Not significant \\
\hline Pure Error & $4.471 \times 10^{6}$ & 5 & $8.942 \times 10^{5}$ & - & - & \\
\hline Cor Total & $5.043 \times 10^{8}$ & 29 & - & - & - & \\
\hline $\mathrm{R}^{2}$ & & 0.8568 & & Adj $R^{2}$ & & 0.8112 \\
\hline Pred $R^{2}$ & & 0.7008 & & Adeq Precision & & 17.048 \\
\hline
\end{tabular}

Table 6. Analysis of variance on wear volume.

\subsection{Analysis of the Micro-Hardness Model}

The plot of the residual factor for the micro-hardness model is shown in Figure 3a. The almost linear distribution of the plot indicates an exceptional fit to the model. Figure $3 \mathrm{~b}$ shows the small-scale error between the predicted and actual micro-hardness experimental values, which demonstrates this model has high prediction accuracy.

Figure 4 shows laser power to be positively correlated to micro-hardness and scanning speed to be negatively correlated with micro-hardness. This phenomenon is due to the fact that laser power defines the amount of energy absorbed by the powder during laser cladding. With other conditions being the same, higher laser power corresponds to more energy being absorbed. Element analysis by EDS of the cladding layer cross section was performed on samples made with $6 \mathrm{~mm} / \mathrm{s}$ scanning speed, $1200 \mathrm{~L} / \mathrm{h}$ gas flow, $40 \%$ TiC powder ratio, and laser power of $1.1 \mathrm{~kW}$ (Figure 5) and $1.5 \mathrm{~kW}$ (Figure 6). Iron content in the cladding layer increased with the higher laser power. The distribution of 
iron is relatively even in Figure 5 due to the effects of elemental diffusion. However, the distribution of iron in Figure 6 decreases from bottom to top, which results from more iron being diffused into the cladding layer since higher laser power promotes more intensive elements diffusion. A higher laser power causes an increase in $\mathrm{TiC}$ melting and an increased possibility of nucleation, which creates smaller crystallite and increases the micro-hardness [19-21]. In addition, the scanning speed controls the amount of time the cladding powder is exposed to the laser beam. With the same laser power, a lower scanning speed increased the amount of energy delivered to the cladding material. This condition helps the melting of $\mathrm{TiC}$ and improves the micro-hardness of the cladding layer. On the contrary, a higher scanning speed reduces the exposure time, which reduces the energy delivered to the cladding powder and has an adverse effect on melting of TiC. Thus, increased scanning speed decreases micro-hardness.

Figure 7 shows how the interaction of laser power and the $\mathrm{TiC}$ powder ratio influences micro-hardness. It is evident that the $\mathrm{TiC}$ powder ratio has stronger influence on the cladding layer micro-hardness than the laser power, which is consistent with Table 5. The micro-hardness increases with the $\mathrm{TiC}$ ratio because a known property of $\mathrm{TiC}$ is that it can serve as a hardness enhancement compound.

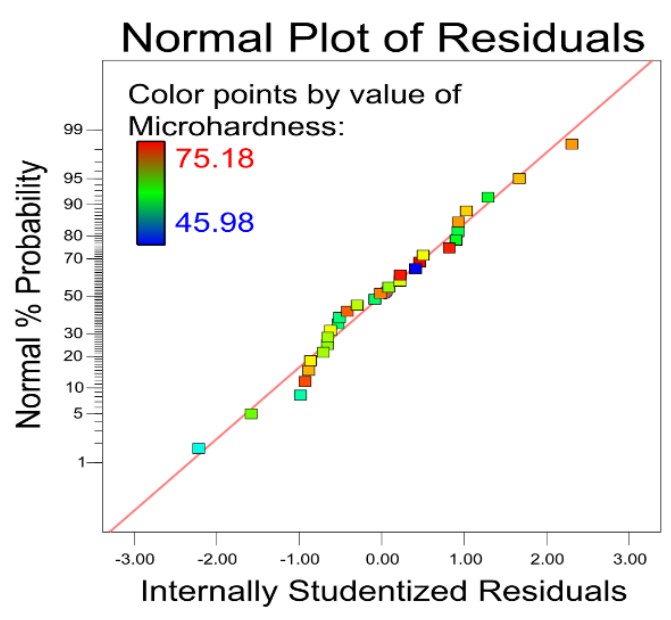

(a)

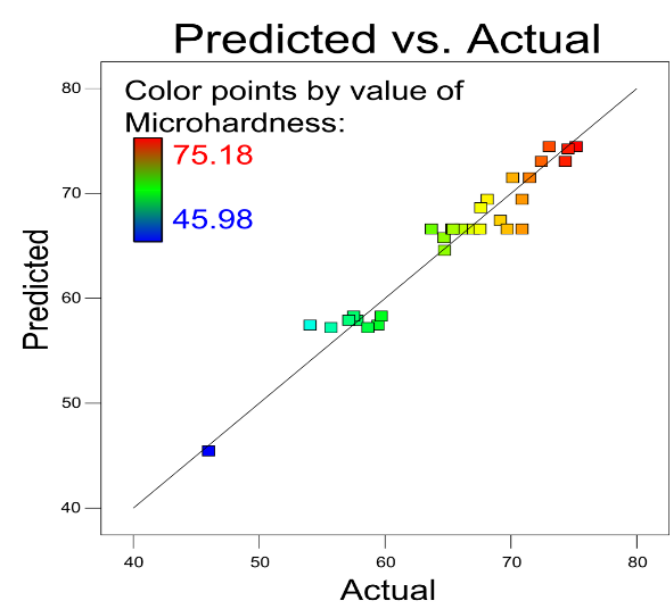

(b)

Figure 3. (a) Residual analysis of micro-hardness. (b) Comparison of predicted and actual micro-hardness.

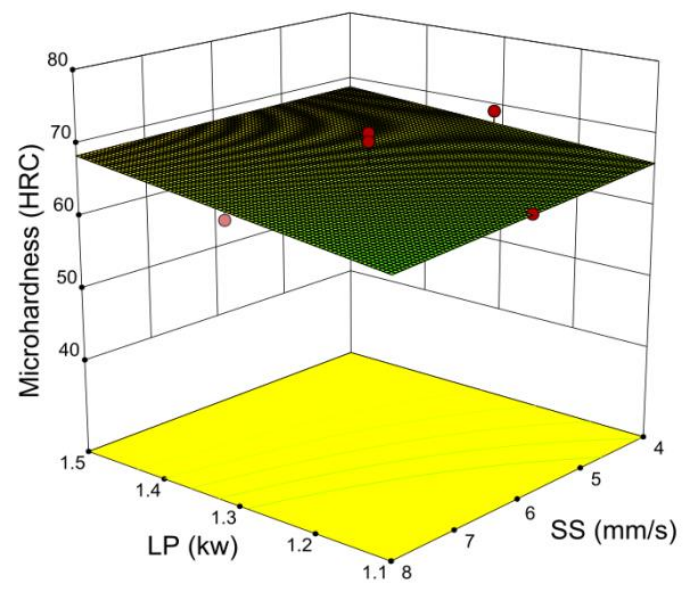

(a)

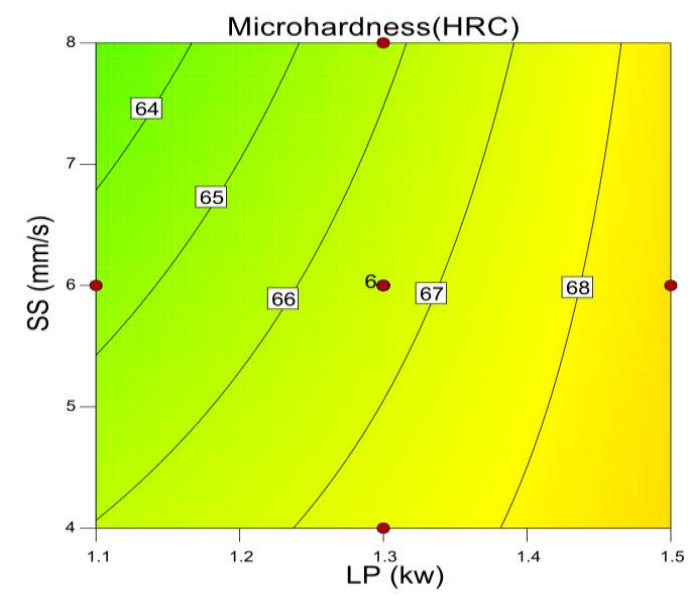

(b)

Figure 4. (a) 3D influence of laser power and scanning speed on micro-hardness. (b) Contour line of laser power and scanning speed on micro-hardness. 


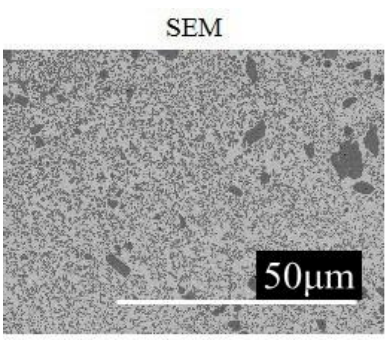

$\mathrm{Fe}$
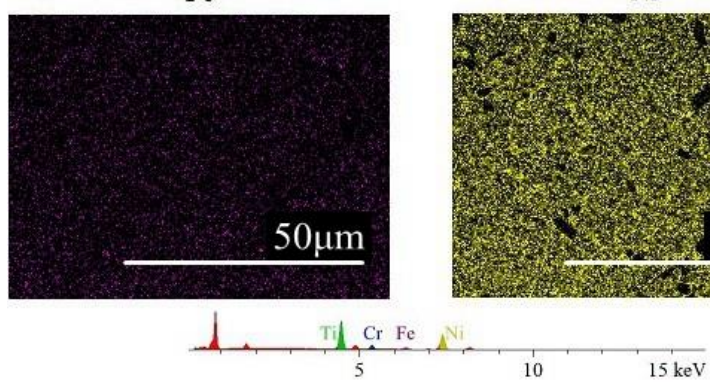

$\mathrm{Ti}$

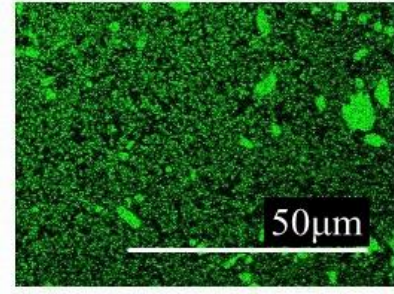

$\mathrm{Ni}$

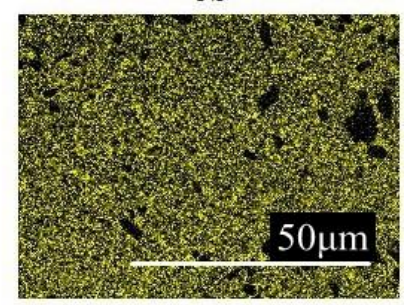

$5 \mathrm{keV}$

Figure 5. Element analysis on the cladding layer cross section (1.1 kW laser power).

SEM

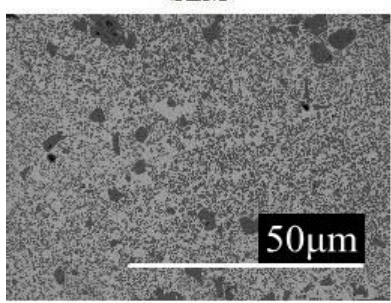

$\mathrm{Fe}$
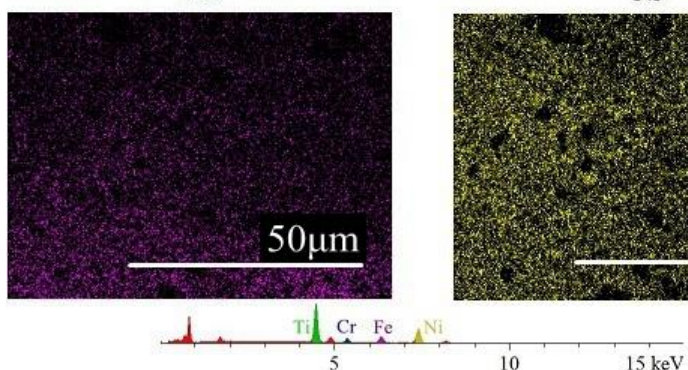

Ti

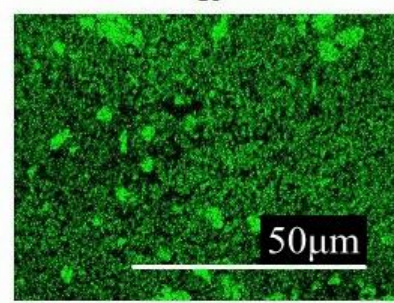

$\mathrm{Ni}$

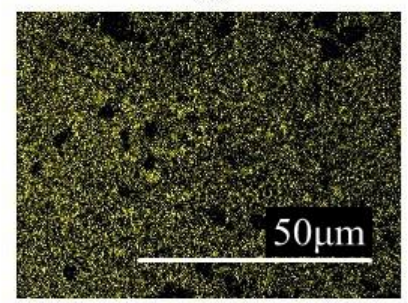

$\mathrm{keV}$

Figure 6. Elements analysis on the cladding layer cross section (1.5 kW laser power).

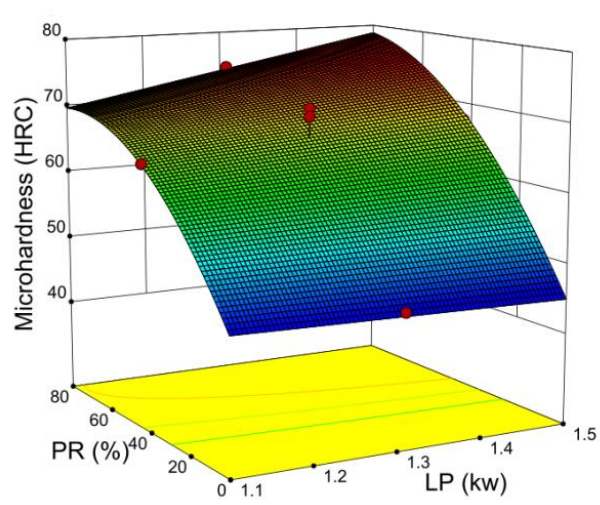

(a)

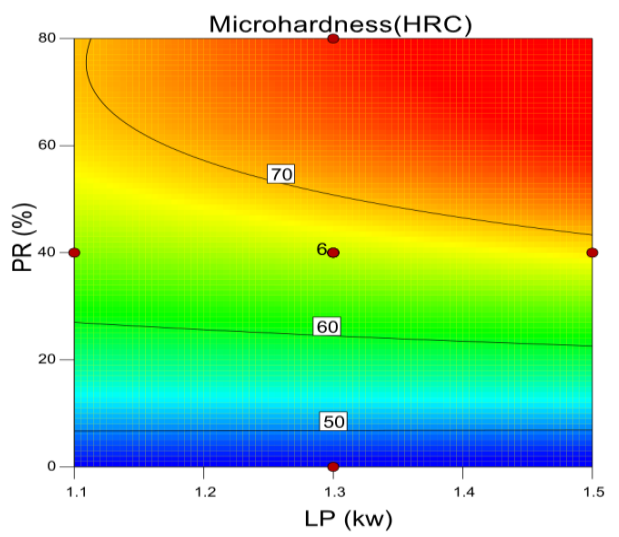

(b)

Figure 7. (a) 3D influence of laser power and TiC powder ratio on micro-hardness. (b) Contour line of laser power and $\mathrm{TiC}$ powder ratio on micro-hardness. 
Figure 8 displays the impact of different parameters on the micro-hardness. The most significant impact on the micro-hardness is the $\mathrm{TiC}$ powder ratio. Laser power is linearly related to micro-hardness and positively correlated. Scanning speed is also linearly related to micro-hardness, but has a negative correlation.

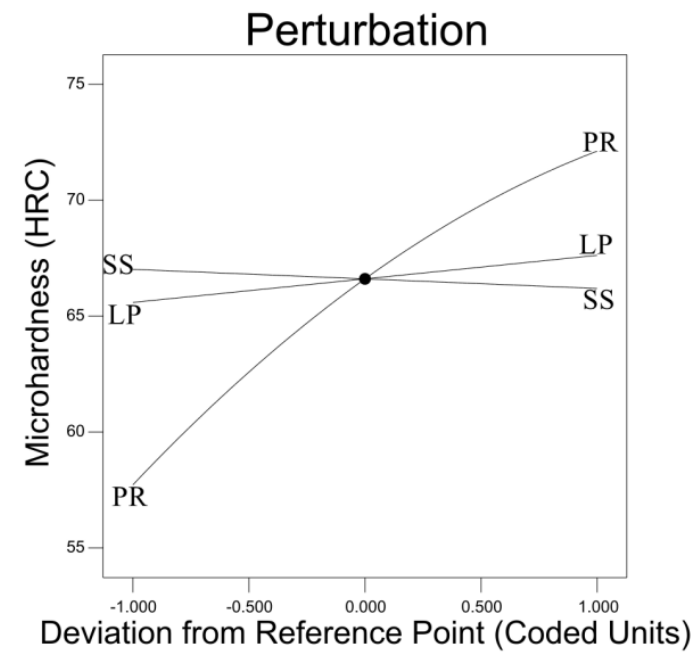

Figure 8. Impact of different parameters on micro-hardness.

\subsection{Analysis of the Wear Volume Model}

From Figure 9, it can conclude that the wear volume model demonstrates exceptional prediction accuracy. The model could effectively account for different processing parameters and accurately predict the wear volume as seen by the nearly linear distribution in Figure 9a and error scale in Figure $9 b$.

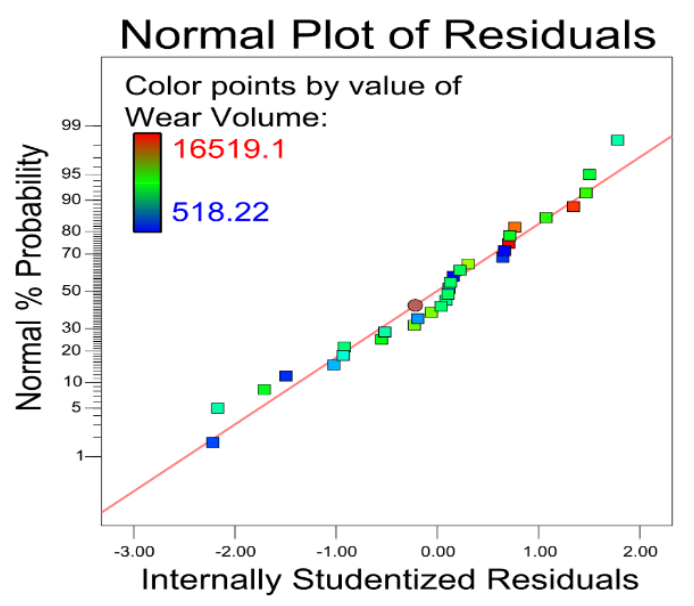

(a)

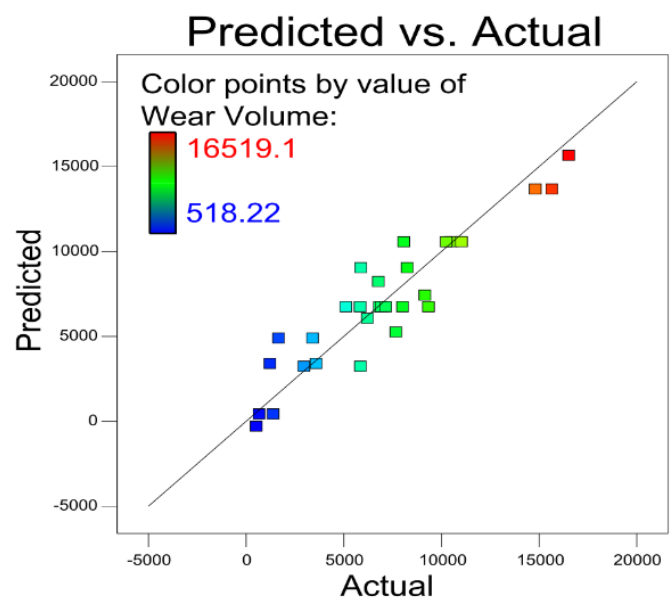

(b)

Figure 9. (a) Residual analysis on wear volume. (b) Comparison of predicted and actual wear volume.

The wear volume of the cladding layer increases as the laser power decreases and the scanning speed increases (Figure 10). Lower laser power results in less energy being absorbed by the cladding layer. In addition, the grain size was measured with the Nano Measurer, where the average grain size is $14.62 \mu \mathrm{m}$ and $18.66 \mu \mathrm{m}$ in the cladding layer obtained with $6 \mathrm{~mm} / \mathrm{s}$ scanning speed, $1200 \mathrm{~L} / \mathrm{h}$ gas flow, $40 \%$ TiC powder ratio, and laser power $1.5 \mathrm{~kW}$ and $1.1 \mathrm{~kW}$, respectively. Therefore, a fine crystal grain could be obtained with higher laser power while other parameters remain the same. In addition, according to the Hall-Petch relation, fine crystal grains will also contribute to increased cladding layer 
micro-hardness [22]. Increasing laser power could aid in grain refinement and nucleation, which decomposes more $\mathrm{TiC}$ and promotes the diffusion of fine grains. Therefore, better wear resistance could be achieved with larger laser power.

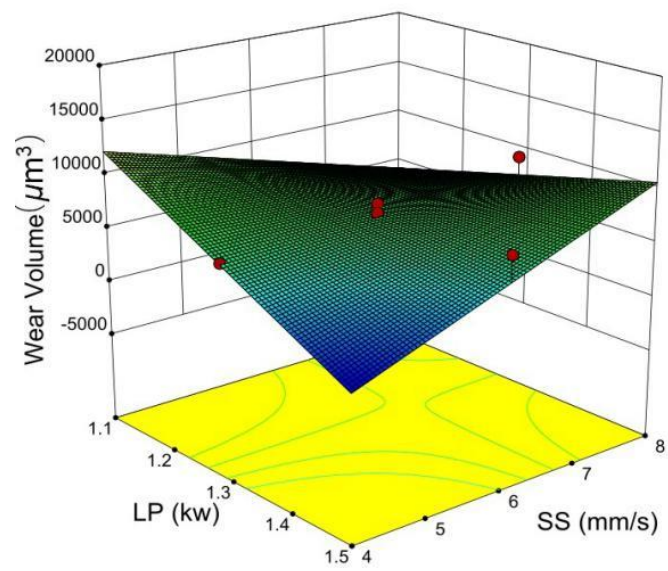

(a)

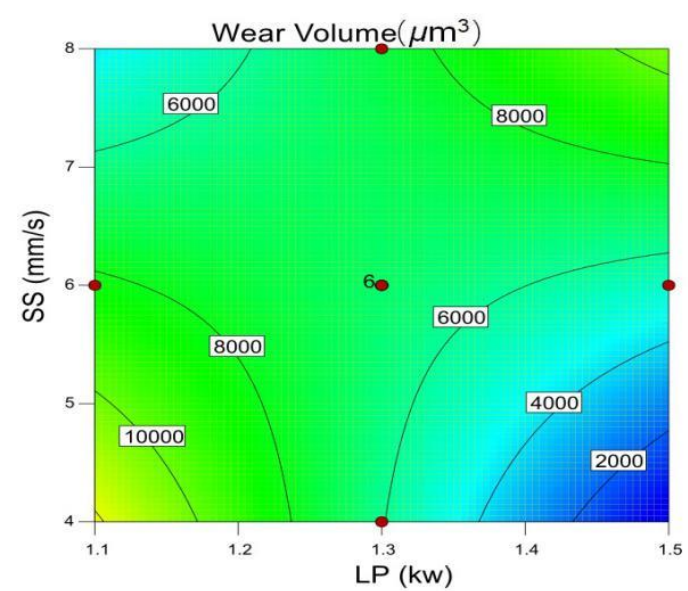

$(\mathbf{b})$

Figure 10. (a) 3D influence of laser power and scanning speed on wear volume. (b) Contour line of laser power and scanning speed on wear volume.

The cladding layers shown in Figure 11 were obtained using a $1.2 \mathrm{~kW}$ laser power, $1400 \mathrm{~L} / \mathrm{h}$ gas flow, $60 \%$ TiC powder ratio, and scanning speeds of $5 \mathrm{~mm} / \mathrm{s}$ and $7 \mathrm{~mm} / \mathrm{s}$. The lower scanning speed results in a longer exposure time, which creates a more uniformed structure and leads to the improved micro-hardness and wear resistance. EDS was used to conduct the element analysis in two areas for each sample. The nickel percentage was much higher in the nickel-based structures area A and C. Titanium percentage was higher in the $\mathrm{TiC}$ dendrite structures area $\mathrm{B}$ and $\mathrm{D}$. The iron percentage in the cladding layer at the $7 \mathrm{~mm} / \mathrm{s}$ scanning speed was lower than at the $5 \mathrm{~mm} / \mathrm{s}$ scanning speed. A higher percentage of iron will enhance solid solution strengthening, which improves the micro-hardness and wear resistance of the cladding layer [22]. Therefore, a faster scanning speed will lead to a lower wear resistance and a larger wear volume.

It can be observed from Figure 12 that the wear volume increases as the $\mathrm{TiC}$ powder ratio decreases. Ni35A powder contains elements of $\mathrm{Fe}, \mathrm{Cr}, \mathrm{B}$, and $\mathrm{Si}$. Rapid melting and solidification during the laser cladding process causes elemental diffusion resulting in super-saturation leading to solid solution strengthening. With the increase of the $\mathrm{TiC}$ powder ratio, second phase and solid solution strengthening significantly increases due to the mixture of the ionic bond, the covalent bond, and the metallic bond within the grain structure. This causes a significant improvement of wear resistance [23-25].

Figure 13 demonstrates the scanning speed positively affected the wear volume and the laser power and $\mathrm{TiC}$ powder ratio negatively affects the wear volume. The $\mathrm{TiC}$ powder ratio has the most significant impact. All of these three processing parameters display a linear relation with wear volume. 


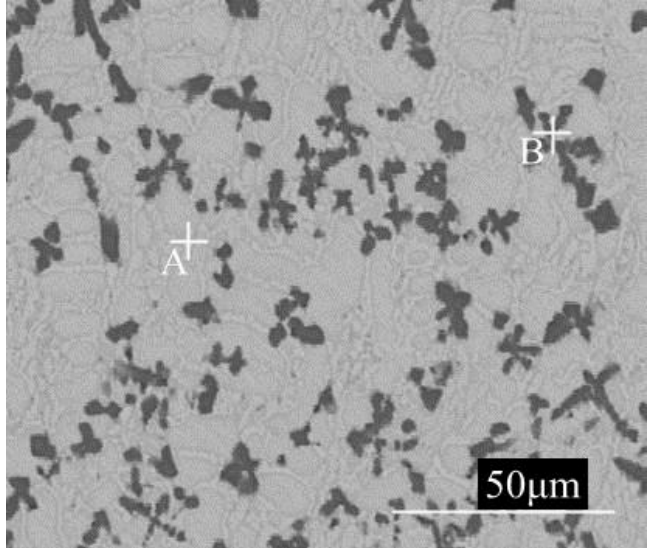

(a)
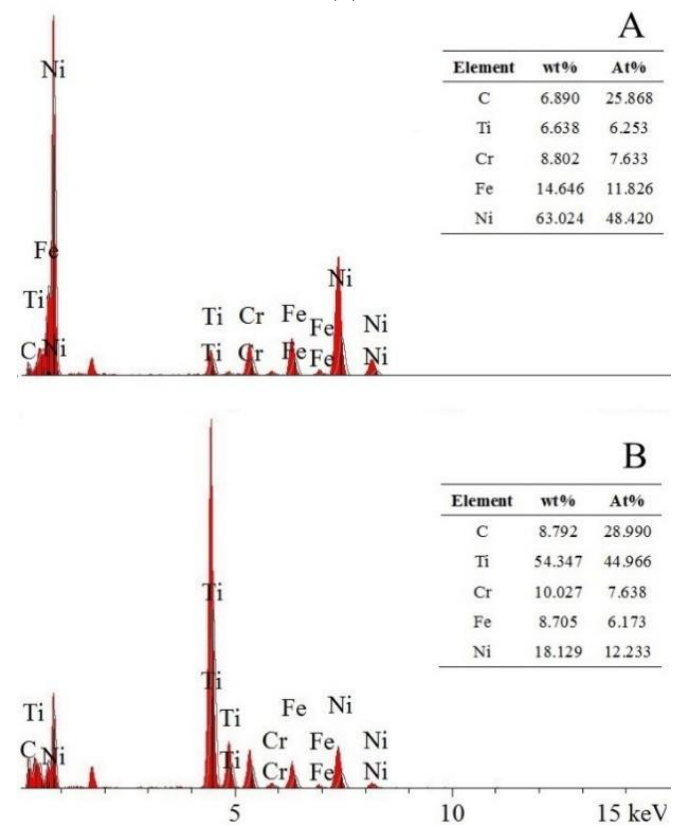

(c)

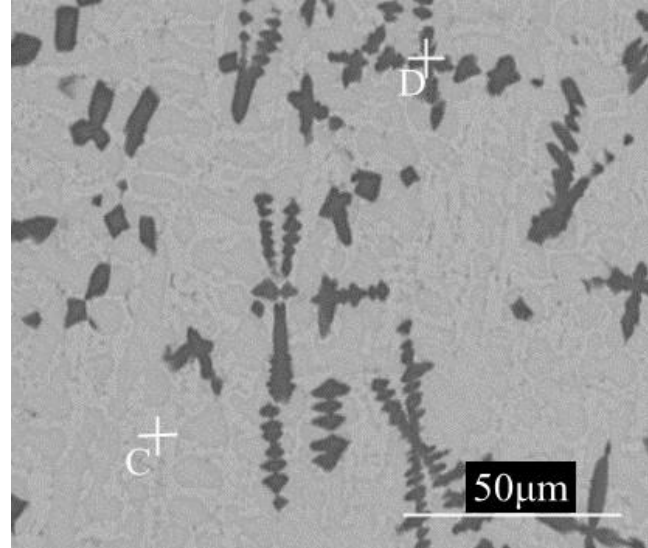

(b)
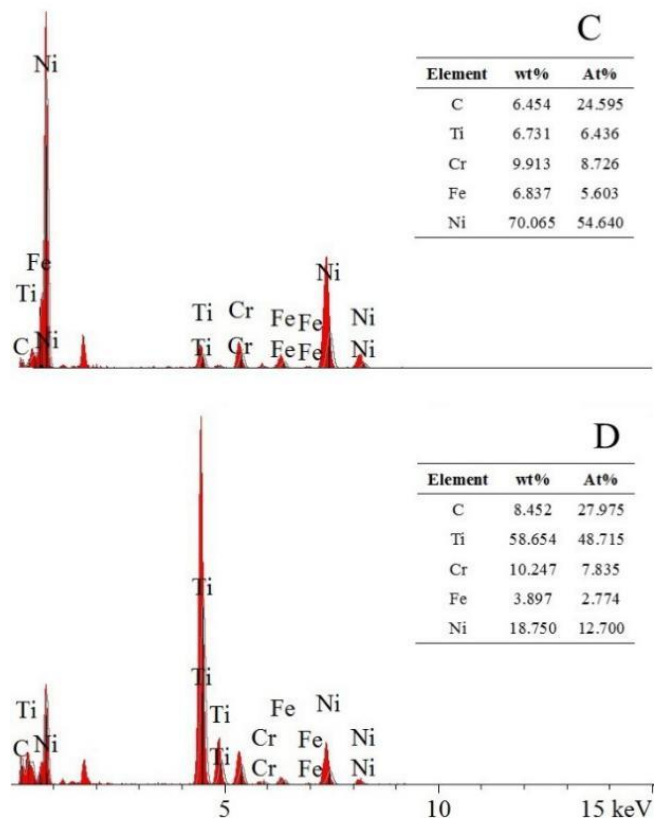

(d)

Figure 11. Structure of the cladding layer made from (a) $5 \mathrm{~mm} / \mathrm{s}$ scanning speed. (b) $7 \mathrm{~mm} / \mathrm{s}$ scanning speed. Element analysis of the cladding layer made from (c) $5 \mathrm{~mm} / \mathrm{s}$ scanning speed. (d) $7 \mathrm{~mm} / \mathrm{s}$ scanning speed.

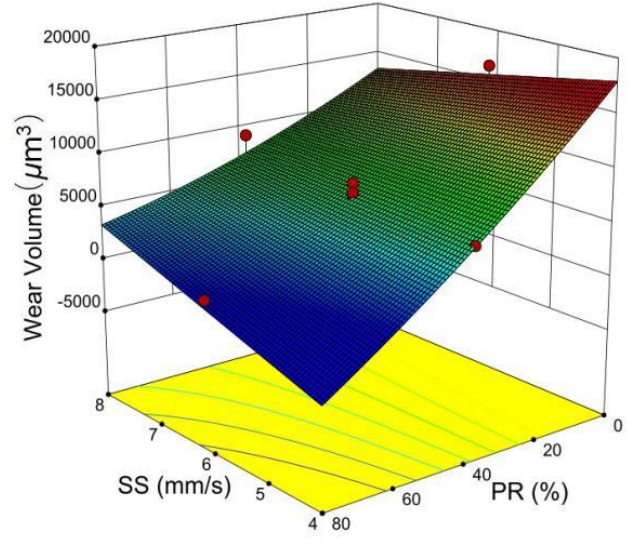

(a)

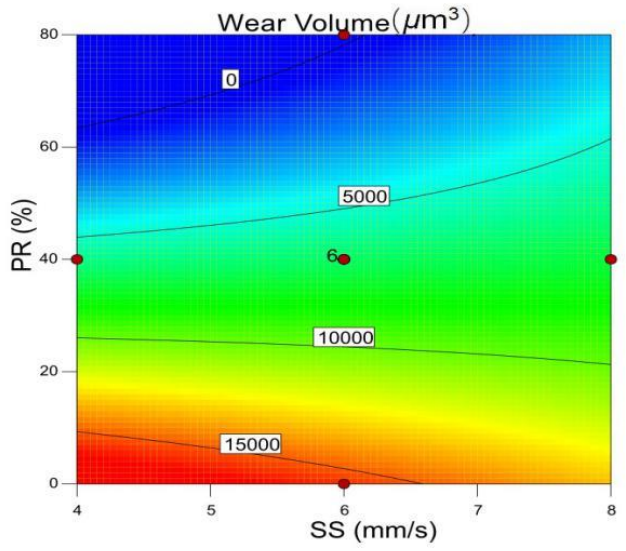

(b)

Figure 12. (a) 3D influence of scanning speed and the TiC powder ratio on wear volume. (b) Contour line of scanning speed and $\mathrm{TiC}$ powder ratio on wear volume. 


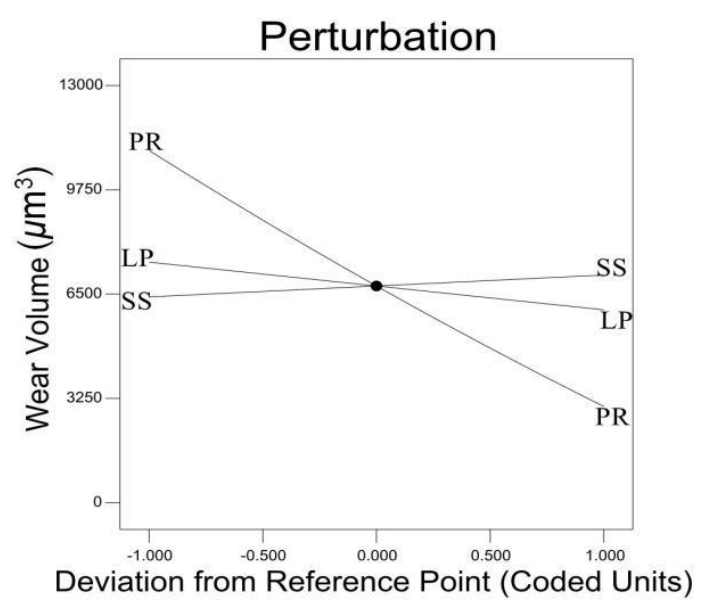

Figure 13. Impact of different parameters on wear volume.

\subsection{Phase Analysis}

Figure 14 shows the XRD diffraction patterns of four randomly selected samples since it is assumed that no phase change would be evolved during laser cladding and only peak intensity would vary. It indicates that the principal phases in the cladding layers are $\mathrm{TiC}$ and $\mathrm{Ni}$. The $\mathrm{TiC}$ was identified as the cubic structure Khamrabaevite (JCPDS: 65-0242). The nickel was identified as the cubic structure Ni (JCPDS: 65-0380). From the same results observed in all the samples, it indicates that phase compositions remain unchanged as the raw material. Moreover, the laser cladding process is mainly a physical reaction and the chemical reaction is negligible.

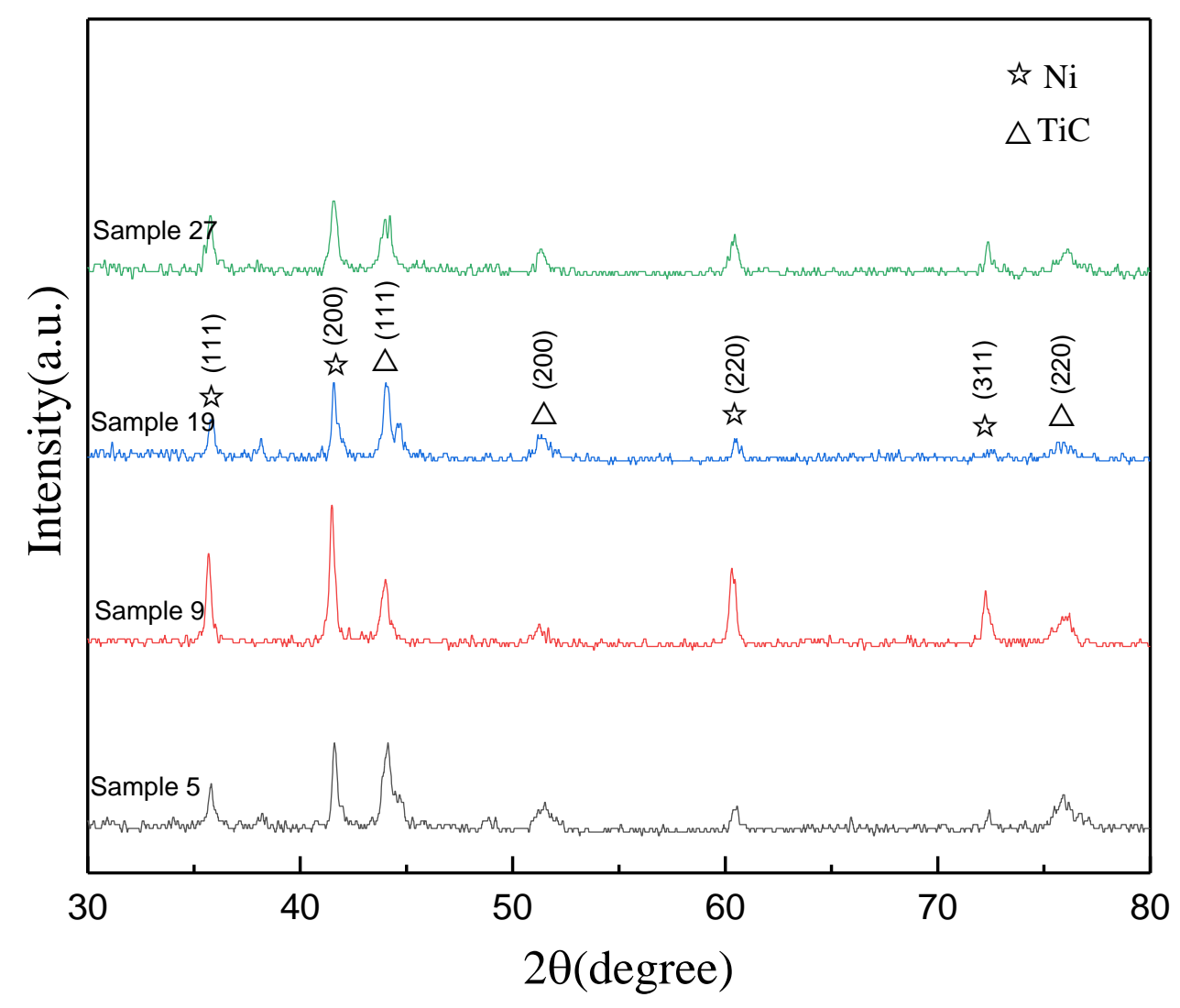

Figure 14. XRD patterns of different samples. 


\subsection{Processing Parameter Optimization and Model Validation}

The criteria and limits of the processing parameters and the response of the optimization are listed in Table 7. Since the micro-hardness and wear volume are important factors to evaluate the quality of the cladding layer, their importance levels are both assigned as five (within range 1-5, larger number, higher importance). The hardness requirement for regular tools of $62 \mathrm{HRC}$ [26] was adopted as the target for micro-hardness. The goal for wear volume was to achieve a minimum value in order to attain higher wear resistance.

Table 7. Optimization criteria and limit.

\begin{tabular}{lccccc}
\hline & & & \multicolumn{2}{c}{ Limit } & \multirow{2}{*}{ Importance } \\
\cline { 4 - 5 } & & Criterion & Lower & Upper & \\
\hline \multirow{3}{*}{ Variable } & Laser power & In range & 1.1 & 1.5 & 3 \\
& Scanning speed & In range & 4 & 8 & 3 \\
& Gas flow rate & In range & 800 & 1600 & 3 \\
& TiC powder ratio & In range & 0 & 80 & 3 \\
\hline \multirow{2}{*}{ Response } & Micro-hardness & Target $=62$ & 45.98 & 75.18 & 5 \\
& Wear volume & Minimize & 518.22 & $16,519.10$ & 5 \\
\hline
\end{tabular}

The optimal parameters were found to be a laser power of $1.5 \mathrm{~kW}$, scanning speed of $4 \mathrm{~mm} / \mathrm{s}$, gas flow of $1408.558 \mathrm{~L} / \mathrm{h}$, and TiC powder ratio of $26.964 \%$ (Table 8 ). Based on limitation of the equipment set point accuracy, the test parameters of the validation experiment were set as a laser power of $1.5 \mathrm{~kW}$, scanning speed of $4 \mathrm{~mm} / \mathrm{s}$, gas flow of $1400 \mathrm{~L} / \mathrm{h}$, and TiC powder ratio of $27 \%$. The micro-hardness and wear volume of the predicted and experimentally validated values are also shown in Table 8 . The error of the prediction was calculated to be $1.87 \%$ for micro-hardness and $6.33 \%$ for wear volume.

Table 8. Optimization result and parameter selection of the validation experiment.

\begin{tabular}{lcccccccc}
\hline & $\begin{array}{c}\text { LP } \\
(\mathbf{k W})\end{array}$ & $\begin{array}{c}\text { SS } \\
(\mathbf{m m} / \mathbf{s})\end{array}$ & GF (L/h) & $\begin{array}{c}\text { PR } \\
(\mathbf{w t . \% )}\end{array}$ & Micro-Hardness & $\begin{array}{c}\text { Wear } \\
\text { Volume }\end{array}$ & Desirability & \\
\hline Prediction & 1.5 & 4 & 1408.558 & 26.964 & 62 & 3067.37 & 0.917 & Selected \\
Validation & 1.5 & 4 & 1400 & 27 & 63.16 & 3261.57 & - & - \\
\hline
\end{tabular}

Figure 15a shows that the friction coefficient of the cladding layer to increase for the first $10 \mathrm{~min}$ then stabilizes at a value of approximately 0.25 . The friction coefficient of the substrate also increases over time and stabilizes around 0.61 . The difference in the coefficient of friction between the cladding layer and the substrate can be explained by the $\mathrm{TiC}$ powder ratio of $27 \%$ in the cladding layer, which promotes more second-phase strengthening and improves its wear resistance. The furrow wear and a large amount of peeling observed in the substrate (Figure 15b) was not observed in the cladding layer (Figure 15c) due to the solid solution strengthening from $\mathrm{TiC}$ and second-phase strengthening. Second-phase strengthening had protected the pressing of the grinding head with only slight scratches being observed. It demonstrates that application of a cladding layer with an optimized parameter can be an effective surface modification method.

The 3D morphology of the worn area is shown in Figure 16. The wear volume of AISI/SAE 1045 steel was $20,114.36 \mu^{3}$ (Figure 16a) and the wear volume of the cladding layer with optimized parameters was $3261.57 \mu \mathrm{m}^{3}$ (Figure 16b). Under the same testing conditions, the wear volume of the substrate enhanced by the cladding layer was reduced $83.8 \%$ compared with the substrate. The cladding layer improved the wear resistance 6.17 times when compared to the AISI/SAE 1045 steel substrate without cladding. 


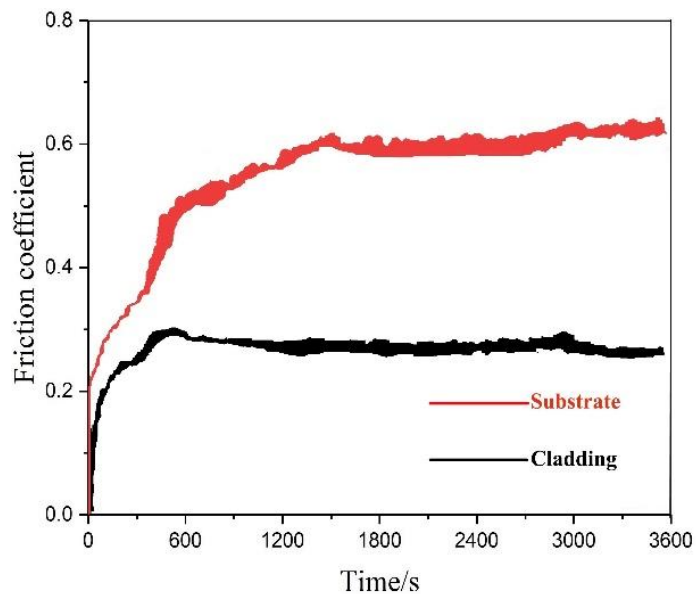

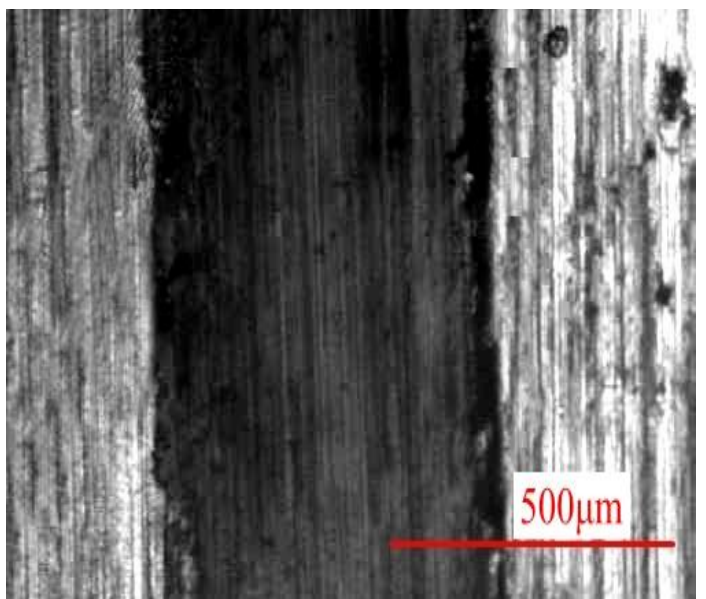

(b)

(a)

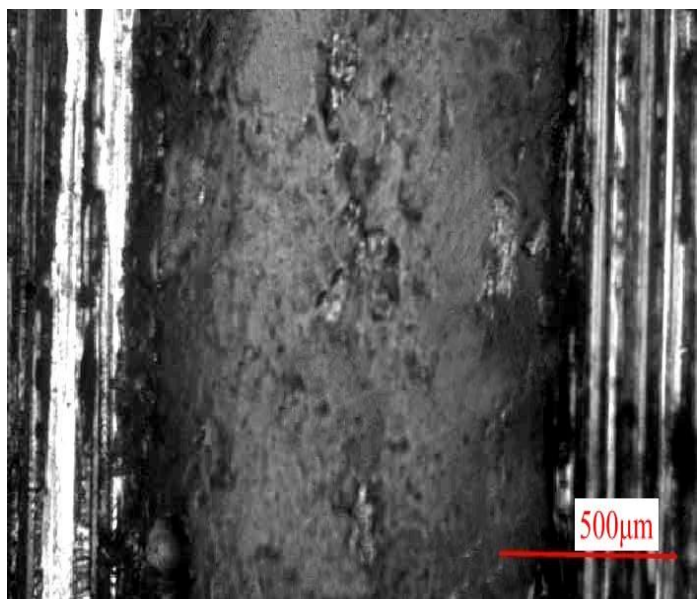

(c)

Figure 15. (a) Friction coefficient curve of the cladding layer and substrate. (b) Wear morphology of the cladding layer made with optimized parameters. (c) Wear morphology of the substrate without a cladding layer.

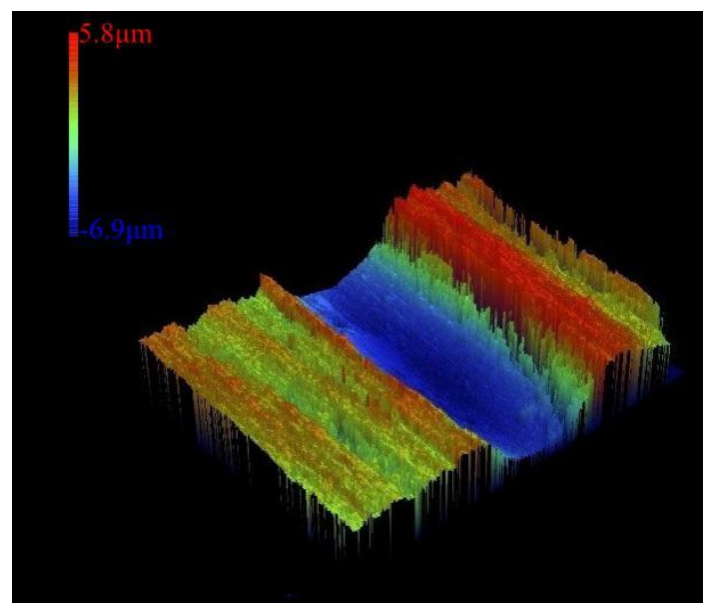

(a)

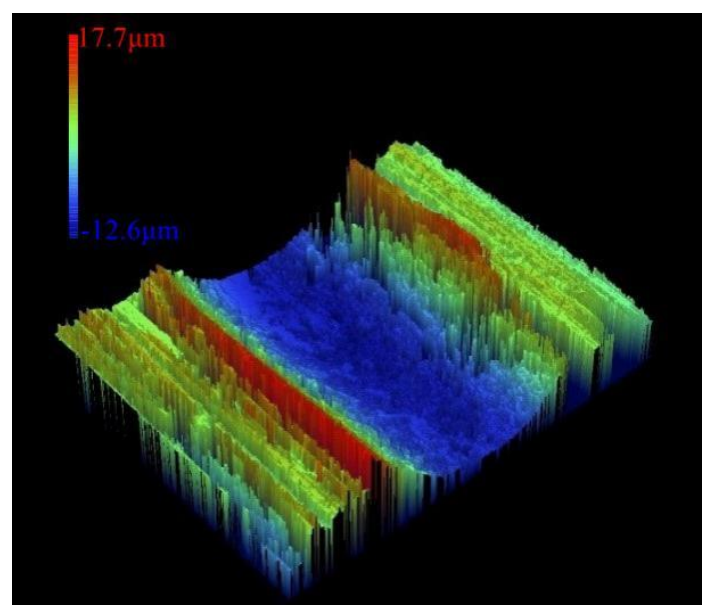

(b)

Figure 16. (a) Wear on the cladding layer. (b) Wear on the substrate.

\section{Conclusions}

This research developed the models relating the laser cladding processing parameters (laser power, scanning speed, gas flow, and $\mathrm{TiC}$ powder ratio) of a composite material cladding layer to the 
micro-hardness and wear volume through response surface methodology. A validation experiment conducted with optimized processing parameters verified the reliability of these models. These models provide guidance for processing parameters optimization, composite material cladding layer property prediction, and control. Conclusions can be drawn as follows:

1. A near linear relationship exists between micro-hardness and processing parameters. Microhardness is primarily affected by the TiC powder ratio. A higher micro-hardness in the cladding layer can be obtained by increasing the $\mathrm{TiC}$ powder ratio, increasing the laser power, and decreasing scanning speed.

2. The correlation between wear volume and processing parameters also appears to be linear. TiC powder ratio has a major influence on the wear volume of the cladding layer. Increasing laser power and $\mathrm{TiC}$ powder ratio and decreasing scanning speed could achieve smaller wear volume.

3. Enhancing the surface of the substrate by applying a cladding layer with optimal processing parameters increased the wear resistance by approximately 6.17 times and reduced the wear volume by about $83.8 \%$.

Author Contributions: Methodology, G.L. and H.Z. Experiment, H.Z. Analysis, G.L., H.Z., Y.Z., and X.H. Writing_original draft preparation, G.L. and H.Z. Writing - review and editing, Y.Z., M.Y., and C.C. Supervision, G.L. and Y.Z.

Funding: This research was funded by The National Natural Science Foundation of China, grant number 51575110.

Acknowledgments: The authors gratefully acknowledge the support from the Public Service Platform for Technical Innovation of Machine Tool Industry in Fujian Province at the Fujian University of Technology.

Conflicts of Interest: The authors declare no conflict of interest.

\section{References}

1. Li, C.; Yu, Z.; Gao, J.; Zhao, J.; Han, X. Numerical simulation and experimental study of cladding Fe60 on an ASTM 1045 substrate by laser cladding. Surface Coat. Technol. 2019, 357, 965-977. [CrossRef]

2. More, S.R.; Bhatt, D.V.; Menghani, J.V. Resent Research Status on Laser Cladding as Erosion Resistance Technique-An Overview. Mater. Today Proc. 2017, 4, 9902-9908. [CrossRef]

3. Weng, F.; Chen, C.; Yu, H. Research status of laser cladding on titanium and its alloys: A review. Mater. Des. 2014, 58, 412-425. [CrossRef]

4. Riveiro, A.; Mejías, A.; Lusquiños, F.; del Val, J.; Comesaña, R.; Pardo, J.; Pou, J. Optimization of laser cladding for Al coating production. Phys. Procedia 2013, 41, 327-334. [CrossRef]

5. Liu, J.; Yu, H.; Chen, C.; Weng, F.; Dai, J. Research and development status of laser cladding on magnesium alloys: A review. Opt. Lasers Eng. 2017, 93, 195-210. [CrossRef]

6. Zhang, C.-H.; Wu, C.-L.; Zhang, S.; Jia, Y.-F.; Guan, M.; Tan, J.-Z.; Lin, B. Laser cladding of NiCrSiB on Monel 400 to enhance cavitation erosion and corrosion resistance. Rare Metals 2016, 1-9. [CrossRef]

7. Luo, X.; Li, J.; Li, G. Effect of NiCrBSi content on microstructural evolution, cracking susceptibility and wear behaviors of laser cladding WC/Ni-NiCrBSi composite coatings. J. Alloys Compd. 2015, 626, 102-111. [CrossRef]

8. Arias-González, F.; Del Val, J.; Comesaña, R.; Penide, J.; Lusquiños, F.; Quintero, F.; Riveiro, A.; Boutinguiza, M.; Pou, J. Fiber laser cladding of nickel-based alloy on cast iron. Appl. Surface Sci. 2016, 374, 197-205. [CrossRef]

9. Luo, F.; Cockburn, A.; Sparkes, M.; Lupoi, R.; Chen, Z.-J.; O'neill, W.; Yao, J.-H.; Liu, R. Performance characterization of Ni60-WC coating on steel processed with supersonic laser deposition. Defence Technol. 2015, 11, 35-47. [CrossRef]

10. Li, N.; Xiong, Y.; Xiong, H.; Shi, G.; Blackburn, J.; Liu, W.; Qin, R. Microstructure, formation mechanism and property characterization of $\mathrm{Ti}+\mathrm{SiC}$ laser cladded coatings on Ti6Al4V alloy. Mater. Charact. 2019, 148, 43-51. [CrossRef]

11. El-Labban, H.F.; Mahmoud, E.R.I.; Algahtani, A. Microstructure, wear, and corrosion characteristics of TiC-laser surface cladding on low-carbon steel. Metall. Mater. Trans. B 2016, 47, 974-982. [CrossRef] 
12. Bakkar, A.; Ahmed, M.M.; Alsaleh, N.A.; Seleman, M.M.E.-S.; Ataya, S. Microstructure, wear, and corrosion characterization of high TiC content Inconel 625 matrix composites. J. Mater. Res. Technol. 2018, in press. [CrossRef]

13. Muvvala, G.; Karmakar, D.P.; Nath, A.K. In-process detection of microstructural changes in laser cladding of in-situ Inconel 718/ TiC metal matrix composite coating. J. Alloys Compd. 2018, 740, 545-558. [CrossRef]

14. Liu, Y.; Ding, J.; Qu, W.; Su, Y.; Yu, Z. Microstructure evolution of TiC particles In situ, synthesized by laser cladding. Materials 2017, 10, 281. [CrossRef] [PubMed]

15. Saroj, S.; Sahoo, C.K.; Masanta, M. Microstructure and mechanical performance of TiC-Inconel 825 composite coating deposited on AISI 304 steel by TIG cladding process. J. Mater. Process. Technol. 2017, 249, 490-501. [CrossRef]

16. Sahoo, C.K.; Masanta, M. Microstructure and mechanical properties of TiC-Ni coating on AISI304 steel produced by TIG cladding process. J. Mater. Process. Technol. 2017, 240, 126-137. [CrossRef]

17. Alam, M.K.; Urbanic, R.J.; Nazemi, N.; Edrisy, A. Predictive modeling and the effect of process parameters on the hardness and bead characteristics for laser-cladded stainless steel. Int. J. Adv. Manuf. Technol. 2018, 94, 397-413. [CrossRef]

18. Olakanmi, E.; Nyadongo, S.; Malikongwa, K.; Lawal, S.; Botes, A.; Pityana, S. Multi-variable optimisation of the quality characteristics of fiber-laser cladded Inconel-625 composite coatings. Surface Coat. Technol. 2019, 357, 289-303. [CrossRef]

19. Yang, S.; Liu, W.; Zhong, M.; Wang, Z. TiC reinforced composite coating produced by powder feeding laser cladding. Mater. Lett. 2004, 58, 2958-2962. [CrossRef]

20. Emamian, A.; Corbin, S.F.; Khajepour, A. Tribology characteristics of in-situ laser deposition of Fe-TiC. Surface Coat. Technol. 2012, 206, 4495-4501. [CrossRef]

21. He, S.; Fan, X.A.; Chang, Q.; Xiao, L. TiC-Fe-based composite coating prepared by self-propagating high-temperature synthesis. Metall. Mater. Trans. B 2017, 48, 1748-1753. [CrossRef]

22. Han, T.; Xiao, M.; Zhang, Y.; Shen, Y. Effect of Cr content on microstructure and properties of $\mathrm{Ni}-\mathrm{Ti}-\mathrm{xCr}$ coatings by laser cladding. Optik 2019, 179, 1042-1048. [CrossRef]

23. Tao, X.; Zhang, S.; Zhang, C.; Wu, C.; Chen, J.; Abdullah, A.O. Effect of Fe and Ni contents on microstructure and wear resistance of aluminum bronze coatings on 316 stainless steel by laser cladding. Surface Coat. Technol. 2018, 342, 76-84. [CrossRef]

24. Yang, C.; Cheng, X.; Tang, H.; Tian, X.; Liu, D. Influence of microstructures and wear behaviors of the microalloyed coatings on TC11 alloy surface using laser cladding technique. Surface Coat. Technol. 2018, 337, 97-103. [CrossRef]

25. Feng, Y.; Feng, K.; Yao, C.; Li, Z.; Sun, J. Microstructure and properties of in-situ synthesized (Ti3Al+ TiB)/Ti composites by laser cladding. Mater. Des. 2018, 157, 258-272. [CrossRef]

26. Lian, G.; Yao, M.; Zhang, Y.; Huang, X. Analysis and Respond Surface Methodology Modeling on Property and Performance of Two-Dimensional Gradient Material Laser Cladding on Die-cutting Tool. Materials 2018, 11, 2052. [CrossRef] [PubMed]

(C) 2019 by the authors. Licensee MDPI, Basel, Switzerland. This article is an open access article distributed under the terms and conditions of the Creative Commons Attribution (CC BY) license (http://creativecommons.org/licenses/by/4.0/). 